\title{
Keragaan Agronomi Tanaman Kelapa Sawit pada Cekaman Kering Periodik
}

\author{
Agronomy Performance of Palm Oil Under Periodic Dry Stress
}

\author{
Rusdi Evizal ${ }^{1^{\star}}$, Lestari Wibowo ${ }^{2}$, Hery Novpriasyah ${ }^{3}$, Sarno $^{3}$, Rina Yunika Sari ${ }^{1}$, \\ Fembriarti Erry Prasmatiwi ${ }^{4}$ \\ 1 Jurusan Agroteknologi Fakultas Pertanian Universitas Lampung, Bandar Lampung, 35141
2. Jurusan Proteksi Tanaman Fakultas Pertanian Universitas Lampung, Bandar Lampung, 35141
3. Jurusan Ilmu Tanah Fakultas Pertanian Universitas Lampung, Bandar Lampung, 35141
4. Jurusan Agribisnis Fakultas Pertanian Universitas Lampung, Bandar Lampung, 35141
}

*Email: rusdi.evizal@fp.unila.ac.id

Disubmit: 14 September 2019 Direvisi: 24 Desember 2019 Diterima: 20 Januari 2020

\begin{abstract}
Abstrak: Variabilitas iklim seperti musim kering, defisit air, dan "dry spell" sangat mempengaruhi pertumbuhan dan hasil kelapa sawit. Penelitian ini bertujuan mempelajari keragaan agronomi tanaman kelapa sawit akibat kekeringan periodik khususnya pada periode 2011-2015 di perkebunan swasta di Lampung yang mengelola 4900 ha kebun sawit. Pengamatan dilakukan pada JuniSeptember 2016 (setahun setelah kemarau panjang 2015) untuk mengumpulkan data agronomi dari pohon sawit yang dipilih secara random dari blok kebun yang ditentukan secara purposif mewakili tanaman sawit muda (umur 3-8 tahun), remaja (umur 9-13 tahun), dewasa (umur 14-20 tahun), dan tua (umur 21-24 tahun). Data sekunder produksi dan iklim dari perusahaan dan Stasiun Pengamatan Iklim Radin Intan. Hasilnya menunjukkan bahwa perkebunan kelapa sawit di Lampung menghadapi kekeringan periodik yang mempengaruhi pertumbuhan dan produksi. Pada periode 2011-2015 ada 35 bulan kering dengan defisit air $190 \mathrm{~mm}$ (stadium I), 285-359 mm (stadium II) dan $406 \mathrm{~mm}$ (stadium III), dengan dry spell maksimum mencapai 45-51 hari (kategori kekeringan sangat panjang) sampai 126 (kategori kekeringan ekstrim). Keragaan agronomi ditunjukkan oleh rendahnya tegakan pohon per hektar (SPH) dengan model penurunan SPH tertinggi $y=-2,8649 x+150,99$ (nilai $R 2=0,89, x=$ umur kelapa sawit). Kebun kelapa sawit tua memiliki SPH yang rendah. Setahun setelah kemarau pohon tua yang memiliki lebih banyak pelepah patah dan lebih sedikit bunga betina yang mengindikasikan pengaruh kekeringan yang berat. Produksi tandan tidak berbeda nyata antar kategori umur kelapa sawit
\end{abstract}

Kata kunci: Agronomi, kekeringan, kelapa sawit, SPH

Abstract: Climate variability including drought, water deficit, and dry spell considerably affect oil palm growth and yield. This research was aimed to study agronomic performance of oil palm under periodic drought especially in year 2011-2015 in a private plantation in Lampung Province, Indonesia, that managed 4900 ha of oil palm plantation. An observation was conducted on June-September 2016 (a year after long drought 2015) to collect agronomic data of oil palm trees that randomly sampled. The oil palm block farms were purposively sampled representing young (3-8 years), teenage (9-13 years), mature (14-20 years), and old trees (21-24 years). We collected the secondary data from the company and Radin Intan Climate Station. The results showed that oil palm plantation in Lampung faced a periodic drought that effect growth and yield. In period year 2011-2015, there were 3-5 dry months consisted of water deficit of $190 \mathrm{~mm}$ (drought stadium I), 285-359 $\mathrm{mm}$ (drought stadium II), and 406 $\mathrm{mm}$ (drought stadium III) with maximum dry spell of 45-51 days (long drought) up to 126 days (extreme drought). Agronomic performance showed a low stand per hectare (SPH) which the highest decreasing model of SPH was $y=-2.8649 x+150.99(R 2=0.89, x=$ trees age). The farms of old palm oil trees had low SPH. A year after long drought, old trees characterized by more broken leaf and less female flower indicating higher drought severity. Bunch production was not significantly different among age categories of oil palm trees.

Keywords: Agronomic, drought, oil palm, SPH 


\section{PENDAHULUAN}

Tanaman kelapa sawit dapat berproduksi optimal pada areal dengan curah hujan yang relatif tinggi yaitu lebih dari $2000 \mathrm{~mm}^{\text {tahun }}{ }^{-1}$ dan terdistribusi merata sepanjang tahun, tanpa adanya bulan kering, atau tanpa periode kering yang tegas (Hartley, 1977; Murtilaksono, Siregar dan Darmosarkoro, 2007). Menurut Djaenudin et al. (2011) kelas kesesuaian lahan S3 untuk kelapa sawit apabila rata-rata temperatur udara $32-35^{\circ} \mathrm{C}$, curah hujan $1250-1450 \mathrm{~mm} /$ tahun dengan bulan kering 34 bulan.

Dalam konteks ekofisiologi, faktor lingkungan yang dominan mempengaruhi pertumbuhan tanaman kelapa sawit adalah faktor iklim dan keadaan tanah. Faktor iklim meliputi intensitas sinar matahari, temperatur, curah hujan, dan kelembaban udara, sedangkan syarat tanah meliputi sifat fisik dan kimia tanah. Kelapa sawit dapat tumbuh dengan baik pada daerah tropika basah $15^{\circ} \mathrm{LU}-15^{\circ} \mathrm{LS}$ dengan ketinggian 0-500 $\mathrm{m}$ di atas permukaan laut. Lamanya penyinaran yang baik untuk kelapa sawit adalah 5-7 jam/hari dan lama penyinaran minimum 1600 jam/tahun. Kurangnya penyinaran dapat menyebabkan pertumbuhan melambat, produksi bunga betina menurun, dan gangguan hama serta penyakit meningkat (Corley and Tinker, 2003).

Variabilitas iklim yang berdampak terhadap kelapa sawit adalah cekaman kekeringan dan cekaman kelebihan air (curah hujan, hari hujan, dry spell, bulan basah, bulan kering, bulan lembab, defisit air), dan stress panas (indeks temperatur udara) (Paterson et al. 2015). Keadaan kering menurunkan produksi tandan buah segar (regresi berslope negatif) pada sekitar 7-11 dan 18-23 bulan (lag 7-11 dan lag18-23 bulan) setelah keadaan kering (Legros et al. 2009).

Besarnya kerusakan kelapa sawit akibat kekeringan bergantung pada kondisi tanaman kelapa sawit, periode waktu terjadinya kekeringan, kondisi lahan, dan tingkat kekeringan. Tingkat kekeringan dinyatakan sebagai defisit air, yang terjadi antara lain karena penyebaran hujan yang tidak merata sepanjang tahun (Darmosarkoro, Harahap dan Syamsudin, 2001). Pada kekeringan stadium pertama (defisit air 200-300 mm/tahun) produktivitas TBS menurun $21-32 \%$, sedangkan pada kekeringan stadium lima (defisit $>500$ mm/tahun) produktivitas TBS menurun $54-65 \%$ (Badan Litbang Pertanian, 2011).

\section{METODE PENELITIAN}

Penelitian survei ini dilakukan dengan pengumpulan data di salah satu perkebunan kelapa sawit di Lampung Selatan dengan luas areal kebun sawit 4.900 ha pada bulan April sampai November 2016, setahun setelah kemarau panjang tahun 2015 dengan mengamati aspek agronomi tanaman kelapa sawit dari 4 kategori pada 3 divisi kebun. Data sekunder yang dikumpulkan meliputi data populasi pohon, kematian pohon, pengelolaan kebun, karateristik lahan, produksi dan data iklim 10 terakhir baik dari perusahaan maupu dari Stasiun Pengamatan Iklim Radin Intan.

Defisit air pada kebun kelapa sawit dihitung menggunakan metode Taillez (1973) Dry spell ditentukan paling tidak 10 hari berturut-turut tanpa hujan atau hujan tidak ada yang $\geq 1 \mathrm{~mm}$. Variabel dry spell digunakan variabel length dry spell (LDS) untuk 10 hari ( $D S \geq 10$ ), 20 hari ( $D S \geq 20$ ), 30 hari ( $D S \geq 30$ ), serta frekuensi dry spell (FDS). Dry spell maksimum (hari tanpa hujan terpanjang) berpengaruh penting 
terhadap produksi kelapa sawit (PPKS, 2016) dan dikategorikan menjadi: (1) Sangat pendek (very short) (1-5 hari), (2) Pendek (short) (6-10 hari), (3) Menengah (moderate)(11-20 hari), (4) Panjang (long) (21-30 hari), (5) Sangat panjang (very long) (31-60 hari), dan (6) Kekeringan ekstrim (extreme drought)(>60 hari) (Mathugama and Peiris, 2011).

\section{HASIL DAN PEMBAHASAN}

\section{Variabel Kemarau}

Karakteristik curah hujan di Lampung dalam 11 tahun terakhir disajikan pada Gambar 1 menunjukkan sebaran curah hujan yang tidak merata sepanjang tahun dimana terdapat bulan kering setiap tahun. Jumlah bulan kering (curah hujan $<100$ $\mathrm{mm}$ ) berkisar 1-7 bulan dengan rata-rata 4,2 bulan. Musim kering yang panjang (5-7 bulan) terjadi secara periodik yaitu terjadi sekali setiap tiga tahun.

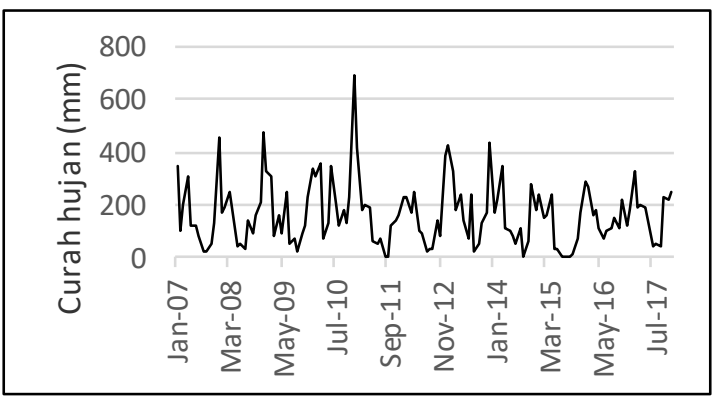

Gambar 1. Sebaran curah hujan di Lampung 2007-2018

Kelapa sawit berproduksi optimal apabila curah hujan lebih dari $2000 \mathrm{~mm}$ per tahun yang terdistribusi merata, artinya tanpa adanya bulan kering, dan curah hujan paling sedikit $150 \mathrm{~mm}$ per bulan untuk mengimbangi besarnya evapotranspirasi (Taillez, 1973).

Dari data curah hujan di lokasi penelitian disajikan sebagai berikut. Dalam periode 2011-2015 ada 2 tahun yang memiliki curah hujan di bawah 2.000 dan ada 4 tahun yang memiliki bulan kering 3-5 bulan dengan defisit air $190 \mathrm{~mm}$ (stadium I), 285-359 mm (stadium II) dan $406 \mathrm{~mm}$ (stadium III). (Murtilaksono, Siregar dan Darmosarkoro (2007) menghitung bahwa evapotransirasi tanaman kelapa sawit sebesar $100 \mathrm{~mm}$ dengan nilai koefisien tanaman (Kc) 1,2. maka jumlah bulan dengan curah hujan $<100 \mathrm{~mm}$ menjadi penting untuk diperhatikan dalam budidaya kelapa sawit.

Beberapa variabel kemarau pada periode 2011-2015 disajikan pada Tabel 1 yang menunjukkan dry spell maksimum 126 hari terjadi pada tahun 2012 sebagai cuaca kering ekstrim yaitu sepanjang 4 bulan tanpa ada hujan sama sekali yang tentu akan sangat berpengaruh pada pertumbuhan dan produksi kelapa sawit. Bahkan pada musim kemarau (Juni-Oktober) dry spell berjumlah 152 hari. Tahun berikutnya 2013 merupakan tahun dengan periode kering yang basah, dengan dry spell maksimum hannya 17 hari dengan curah hujan pada musim kemarau tetap tinggi yaitu $757 \mathrm{~mm}$, kemarau terbasah dalam 5 tahun.

Musim kering yang panjang yang disebut sebagai gejala EI Nino terjadi pada tahun 2015 dimana bulan kering $(<100 \mathrm{~mm})$ mencapai lima bulan dengan periode dry spell mencapai 126 hari dan curah hujan terendah selama 5 tahun yaitu berjumlah 
$1554 \mathrm{~mm}$ tahun $^{-1}$. Maksimum dry spell mencapai 126 termasuk kategori kekeringan ekstrim. Pada tahun berikutnya (2013) diiringi dengan dry spell yang moderat, dan pada tahun 2014 dan 2015 merupakan dry spell berkategori sangat panjang (Tabel 1). Jadi pola dry spell 2011-2015 adalah panjang-ekstrim-moderat- sangat panjang sangat panjang. Diduga dry spell maksimum selama 20 hari merupakan titik kritis bagi tanaman kelapa sawit, karena evapotranspirasi bulanan kelapa sawit mencapai $150 \mathrm{~mm}$, sedangkan cadangan air pada awal bulan kering <200 mm. Darlan et al. (2016) melaporkan El Nino 2015 berdampak pada pertumbuhan dan produksi kelapa sawit.

Tabel 1. Variabel kemarau periode 2011-2015 di lokasi kebun

\begin{tabular}{cccccc}
\hline Variabel kemarau & \multicolumn{5}{c}{ Tahun } \\
\cline { 2 - 6 } & $\mathbf{2 0 1 1}$ & $\mathbf{2 0 1 2}$ & $\mathbf{2 0 1 3}$ & $\mathbf{2 0 1 4}$ & $\mathbf{2 0 1 5}$ \\
\hline Curah hujan (mm/tahun) & 1849 & 1985 & 2868 & 1815 & 1554 \\
Curah hujan semester I (mm) & 1100 & 1319 & 1665 & 1055 & 1092 \\
Curah hujan semester II (mm) & 749 & 666 & 1202 & 760 & 462 \\
Bulan kering <100 & 4 & 3 & 2 & 4 & 5 \\
Dry spell maksimum (hari) & 27 & 126 & 17 & 51 & 46 \\
Extreme dry spell $\geq 30$ (hari) & 0 & 116 & 0 & 51 & 78 \\
Defisit air (mm tahun ${ }^{-1}$ ) & 285 & 359 & 0 & 190 & 406 \\
\hline
\end{tabular}

Jumlah Pohon

Jumlah pohon (SPH, stand per hectar)) dan homogenitas keragaannya sangat penting sebagai variabel kualitas fisik kebun, yang menentukan produksi dan produktivitas unit kebun atau blok kebun (Hidayati et al. 2015). Pada umur 1-2 tahun, jumlah pokok masih 143 pohon sesuai SPH jika jarak penanaman 9x9x9 m segitiga sama sisi. Pada tahun-tahun berikutnya jumlah pokok semakin berkurang karena adanya pokok yang mati akibat keadaan lingkungan maupun penyakit. Populasi yang rendah (pokok <100 per ha) ketika tanaman dewasa (umur 14-20 tahun) akibat banyaknya pohon yang mati karena penyakit busuk batang Ganoderma diharapkan baru terjadi ketika kebun berkategori tua (umur 21-24 tahun). Dalam penelitian ini digunakan klasifikasi populasi kelapa sawit yang digunakan adalah sebagai berikut.

Tabel 2. Klasifikasi SPH

\begin{tabular}{cccc} 
No & Jumlah pokok/ha & \% pokok hidup & Klasifikasi SPH \\
\hline 1 & $>140$ & $100-98$ & Standar SPH \\
2 & $130-140$ & $91-97$ & Sangat tinggi \\
3 & $120-129$ & $84-90$ & Tinggi \\
4 & $100-119$ & $70-83$ & Sedang \\
5 & $80-99$ & $56-69$ & Rendah \\
6 & $<80$ & $<56$ & Sangat rendah \\
\hline
\end{tabular}

Tren penurunan populasi dapat berbeda antar blok kebun. Tren penurunan populasi yang tertinggi terjadi pada Divisi III dan terendah pada Divisi II. Ada kencenderungan populasi yang rendah $(<100$ pohon/ha) terjadi ketika kebun masih masuk dalam kategori dewasa (14-20 tahun) yaitu di Divisi I dan III bahkan sudah terjadi ketika kebun masih dalam kategori remaja (9-13 tahun) yaitu di Divisi V. 
Tabel 3. Model penurunan SPH

\begin{tabular}{cccc}
\hline Divisi & Model SPH & $\mathbf{R}^{2}$ & Faktor pembatas $^{*}$ \\
\hline I & $\mathrm{y}=-2,76 \mathrm{x}+154,17$ & 0,78 & Drainase $50-100 \mathrm{~cm}$, sementasi \\
II & $\mathrm{y}=-1,96 \mathrm{x}+147,69$ & 0,81 & Solum tipis, sementasi \\
III & $\mathrm{y}=-2,86 \mathrm{x}+150,99$ & 0,89 & Lapisan cadas \\
IV & $\mathrm{y}=-2,03 \mathrm{x}+147,08$ & 0,98 & Lapisan cadas \\
V & $\mathrm{y}=-2,54 \mathrm{x}+151,13$ & 0,71 & Rendahan dan berbatu \\
\hline * Sumber: (Balai Penelitian Tanah, 2013) & &
\end{tabular}

Klasifikasi umur kelapa sawit yang umum dipakai adalah tanaman muda (3-8 tahun), tanaman remaja (9-13 tahun), tanaman dewasa (14-20 tahun), tanaman tua (21-24 tahun) dan tanaman renta (>25 tahun). Secara rata-rata, SPH kelapa sawit di lokasi penelitian masih dalam norma, yaitu SPH sangat tinggi pada tanaman muda, SPH tinggi pada tanaman remaja, SPH sedang pada tanaman dewasa dan SPH rendah pada tanaman tua. SPH tanaman dewasa pada Divisi III (92 pohon/ha) masuk katergori rendah. SPH tanaman remaja pada Divisi IV (117 pohon/ha) masuk kategori sedang. SPH tanaman mudanya yaitu 134 pohon/ha adalah terendah dibandingkan divisi lainnya.

Tabel 4. SPH berdasarkan kategori umur

\begin{tabular}{ccccccc}
\hline Klasifikasi & Div I & Div II & Div III & Div IV & Div V & Rerata \\
\hline Muda (3-8) & $139,6^{\text {st }}$ & $137,3^{\text {st }}$ & - & $133,6^{\text {st }}$ & - & $136,8^{\text {st }}$ \\
Remaja (9-13) & $137,9^{\text {st }}$ & $126,5^{\mathrm{t}}$ & $120,8^{\mathrm{t}}$ & $117,6^{\mathrm{s}}$ & $142,2^{\text {sph }}$ & $129,0^{\mathrm{t}}$ \\
Dewasa (14-20) & $101,3^{\mathrm{s}}$ & $110,7^{\mathrm{s}}$ & $92,1^{\mathrm{r}}$ & - & $105,9^{\mathrm{s}}$ & $102,5^{\mathrm{s}}$ \\
Tua (21-24) & $94,6^{\mathrm{r}}$ & $112,4^{\mathrm{s}}$ & $88,5^{\mathrm{r}}$ & $100,4^{\mathrm{s}}$ & $77,9^{\text {st }}$ & $94,8^{\mathrm{r}}$ \\
Renta $(>25)$ & - & - & - & - & - & - \\
\hline sph= & norma sesuai SPH, st = sangat tinggi, $\mathrm{t}=$ tinggi, $\mathrm{s}=$ sedang, $\mathrm{r}=$ rendah, sr = sangat \\
rendah & & &
\end{tabular}

Tabel 5. Laju kematian menurut kategori umur

\begin{tabular}{|c|c|c|c|c|c|c|c|}
\hline \multirow{2}{*}{\multicolumn{2}{|c|}{ Variabel }} & \multicolumn{6}{|c|}{ Kategori umur ${ }^{1}$ tahun tanam } \\
\hline & & \multirow{2}{*}{$\begin{array}{c}\text { T } 1992 \\
279\end{array}$} & \multirow{2}{*}{$\begin{array}{c}\text { T } 1993 \\
225\end{array}$} & \multirow{2}{*}{$\begin{array}{c}\text { T } 1994 \\
35\end{array}$} & \multirow{2}{*}{$\frac{R 2003}{43}$} & \multirow{2}{*}{$\begin{array}{c}\text { M } 2009 \\
246\end{array}$} & \multirow{2}{*}{$\begin{array}{c}\text { M } 2010 \\
7\end{array}$} \\
\hline Sensus $^{2}$ & Luas (ha) & & & & & & \\
\hline \multirow[t]{2}{*}{2012} & $\sum$ pohon & 29104 & 25348 & 3546 & 5570 & 33732 & 994 \\
\hline & Phn/ha & 104,3 & 112,6 & 101,3 & 129,5 & 137,1 & 142 \\
\hline \multirow[t]{2}{*}{2013} & $\sum$ pohon & 28506 & 24906 & 3474 & 5429 & 33586 & 987 \\
\hline & Phn/ha & 102,2 & 110,7 & 99,2 & 126,2 & 136,5 & 141 \\
\hline 2014 & $\sum$ pohon & 28377 & 24809 & 3452 & 5385 & 33453 & 987 \\
\hline 2015 & $\begin{array}{l}\text { Phn/ha } \\
\sum \text { pohon } \\
\text { Phn/ha }\end{array}$ & $\begin{array}{l}101,7 \\
28139 \\
100.8\end{array}$ & $\begin{array}{c}110,3 \\
24638 \\
109.5\end{array}$ & $\begin{array}{l}98,6 \\
3414 \\
97.5\end{array}$ & $\begin{array}{c}125,2 \\
5318 \\
123,8\end{array}$ & $\begin{array}{r}135,9 \\
32977 \\
134.0\end{array}$ & $\begin{array}{l}141 \\
987 \\
141\end{array}$ \\
\hline \multicolumn{2}{|c|}{ Laiu kematian $^{3}$} & 1,15 & 1,05 & 1,26 & 1,95 & 1,02 & 0,33 \\
\hline
\end{tabular}

Pertumbuhan dan Produksi 
Karakteristik komponen pertumbuhan dan produksi tanaman kelapa sawit setahun setelah kemarau panjang (tahun 2015) disajikan sebagai berikut. Klasifikasi umur kelapa sawit adalah tanaman muda (3-8 tahun), tanaman remaja (9-13 tahun), tanaman dewasa (14-20 tahun), tanaman tua (21-24 tahun) dan tanaman renta ( $>25$ tahun). Jumlah daun yang patah (sengkleh) meningkat ketika di akhir musim kemarau yaitu bulan Agustus (Gambar 2). Tanaman tua memiliki daun sengkleh yang relatif lebih banyak yaitu 1-2 pelepah sedangkan pada kategori umur lainnya kurang dari satu pelepah.

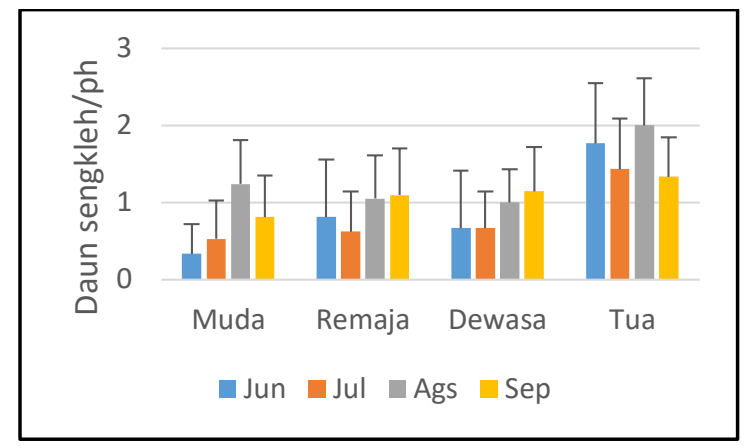

Gambar 2. Daun sengkleh pada kategori umur

Selain daun sengkleh, banyaknya daun tombak yaitu daun muda yang belum mekar, merupakan gejala terjadinya kekeringan pada tanaman kelapa sawit akibat kemarau tahun berjalan. Dalam periode pengamatan bulan Juni-September terdapat 2-3 daun tombak dan tidak ada perbedaan jumlah daun tombak antar kategori umur tanaman kelapa sawit (Gambar 3).

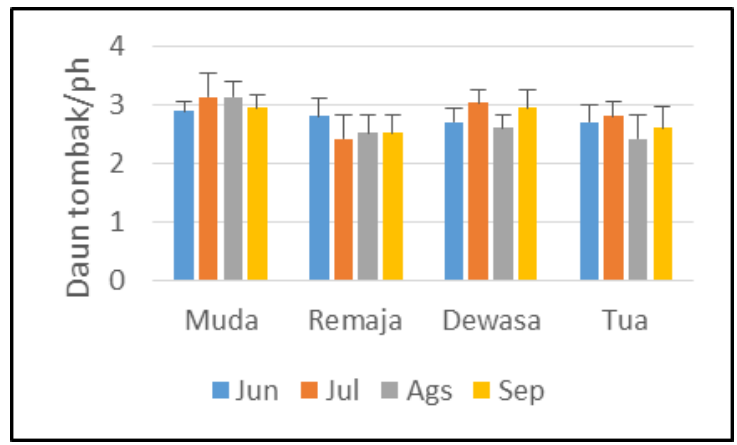

Gambar 3. Daun tombak

Pembungaan merupakan fase generatif yang sangat dipengaruhi musim kering baik tahun sebelumnya maupun tahun berjalan. Selama periode pengamatan, jumlah bunga betina bersifat dinamis dan bervariasi antarapohon. Antar pohon muda dan tua memiliki varibilitas jumlah bunga yang paling tinggi dengan nilai CV 0,26-0,81 sedangkan pada kategori umur remaja dan dewasa nilai CV 0,38-0,55. Jumlah bunga betina menurun pada akhir musim kemarau (Agustus-September). Jumlah bunga betina pada pohon tua relatif lebih rendah daripada kategori umur lainnya yaitu rata-rata kurang dari 1 bunga per pohon (Gambar 4).

Jumlah tandan buah dihitung semua tandan setelah fertilisasi bunga yaitu tandan kategori pentil, cengkir, degan, fraksi 00, dan fraksi 0 yang merupakan indikator produksi tandan dalam 5 bulan ke depan. Jumlah tandan buah bervariasi tinggi antar pohon dengan nilai CV 0,17-0,39. Tidak terdapat perbedaan yang signifikan antar kategori umur pohon. Jumlah tandan pada pohon remaja dan pohon 
tua rata-rata berkisar 3-4 tandan per pohon sedangkan pohon dewasa memiliki 5-6 tandan buah per pohon namun secara statistik tidak berbeda nyata (Gambar 5).

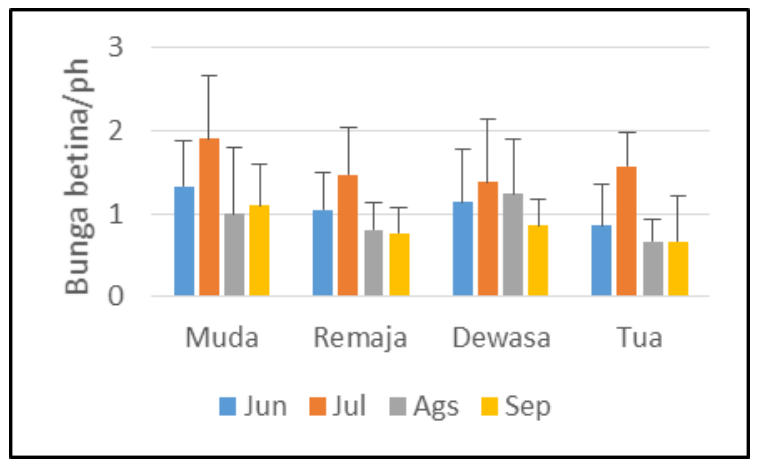

Gambar 4. Jumlah bunga betina

Produksi TBS sangat ditentukan oleh produksi tandan per pohon per tahun dan jumlah SPH (Combres et al. 2013). Pada tanaman muda (umur 3-8 tahun) potensi produksi tandan mencapai lebih dari 15 tandan per pohon per tahun, artinya hampir semua ketiak daun menghasilkan bunga betina dan menjadi buah. Produksi pelepah daun pada periode tersebut mencapai optimal, 3 daun per bulan atau 36 daun per tahun. Menurut Adam et al. (2011) produksi daun pada tanaman dewasa mencapai 2 daun per bulan atau 24 daun per tahun. Hasil penelitian ini menunjukkan bahwa musim kemarau tahun sebelumnya menurunkan produktivitas tandan kelapa sawit menjadi berkisar 3,6-5,4 tandan per pohon per semester.

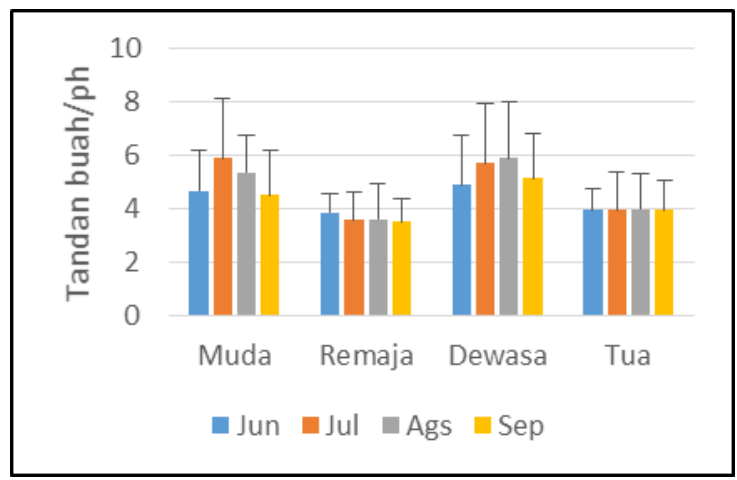

Gambar 5. Jumlah tandan buah

\section{SIMPULAN}

Dari hasil penelitian dapat diambil kesimpulan sebagai berikut: (1) Budidaya kelapa sawit di Lampung menghadapi kekeringan periodik. Pada periode 2011-2015 terdapat bulan kering 3-5 bulan dengan defisit air $190 \mathrm{~mm}$ (stadium I), 285-359 mm (stadium II) dan $406 \mathrm{~mm}$ (stadium III), dengan dry spell maksimum mencapai 45-51 hari (kategori kekeringan sangat panjang) sampai 126 hari (kategori kekeringan ekstrim).(2) Model penurunan populasi terendah adalah dengan nilai R2 adalah 0,89 dan faktor pembatas adanya lapisan cadas. Kebun kelapa sawit tua berpopulasi rendah (80-99 pokok per ha. Kelapa sawit tua memiliki pelepah patah yang lebih banyak dan jumlah bunga betina yang lebih sedikit dibandingkan kategori umur lainnya yang mengindiikasikan kerentanan terhadap kekeringan. Produksi tandan per pohon bervariasi tinggi sehingga tidak berbeda nyata antar kategori umur. 


\section{SANWACANA}

Ucapan terimakasih kepada LPPM Universitas Lampung atas dana penelitian DIPA BLU Tahun 2016.

\section{DAFTAR PUSTAKA}

Adam, H., M. Collin, F. Richaud, T. Beule, D. Cros, A. Omore, L. Nodichao, B. Nouy, and J.W. Tregear. 2011. Environmental Regulation of Sex Determination in Oil Palm: Current Knowledge and Insights from Other Species. Annals of Botany 108(8): 1529-1537.

Badan Litbang Pertanian. 2011. Pedoman Umum Adaptasi Perubahan Iklim Sektor Pertanian, Departemen Pertanian, Jakarta.

Balai Penelitian Tanah. 2013. Usaha Peningkatan Produktivitas dan Pemetaan Kesuburan Tanah pada Tanaman Kelapa Sawit dan Karet di Areal PT Perkebunan Nusantara VII. Bogor.

Combres, J., B. Pallas, L. Rouan, I. Mialet-Serra, J. Caliman, S. Braconnier, J. Soulié and M. Dingkuhn. 2013. Simulation of Inflorescence Dynamics in Oil Palm and Estimation of Environment-Sensitive Phenological Phases: A Model Based Analysis. Functional Plant Biology 40: 263-279.

Corley, R.H.V and P.B. Tinker. 2003. Growth, flowering and yield. In: The Oil Palm, $4^{\text {th }}$ Ed. Oxford: Blackwell Science.

Darlan, N.H., I. Pradiko, Winarna dan H.H. Siregar. 2016. Dampak El Niño 2015 terhadap Performa Tanaman Kelapa Sawit di Sumatera Bagian Tengah dan Selatan. Jurnal Tanah dan Iklim 40(2):113-120.

Darmosarkoro, W., I.Y. Harahap, dan E. Syamsudin. 2001. Pengaruh kekeringan pada tanaman kelapa sawit dan upaya penanggulangannya. Warta PPKS 9(3): 83-96.

Djaenudin, D., H Marwan, H Subagjo, A Hidayat. 2011. Petunjuk Teknis Evaluasi Lahan untuk Komoditas Pertanian. Balai Besar Litbang Sumberdaya Lahan Pertanian. Badan Litbang Pertanian. Bogor.

Hartley, C.W.S. 1977. The Oil Palm. Longman. London.

Hidayati, J., Sukardi, A. Suryani, A.M. Fauzi, and Sugiharto. 2015. Optimization of Palm Oil Plantation Revitalization in North Sumatera Indonesia. International Journal on Advance Science Engineering Information Technology 5(6): 460-468.

Legros, S., I. Mialet-Sera, J.P. Caliman, F.A. Siregar, A. Clement-Vidal, D. Fabre, N. Dingkuh. 2009. Phenology, growth and phtsiological adjustments of oil palm (Elaeis guineensis) to sink limitation induced by fruit pruning. Annals Botany 104: 1183-1194.

Mathugama, S.C and T.S.G. Peiris. 2011. Critical Evaluation of Dry Spell Research., International Journal of Basic and Applied Sciences 11(6): 153-160.

Murtilaksono, K., H.H. Siregar, dan W. Darmosarkoro. 2007. Model neraca air di perkebunan kelapa sawit. Jurnal Penelitian Kelapa Sawit 15(1): 21-35.

Paterson, R.R.M., L. Kumar, S. Taylor, and N. Lima. 2015. Future climate effects on suitability for growth of oil palm in Malaysia and Indonesia. Scientific Reports 5:1445. 
PPKS. 2016. Realisasi dan Prediksi Produksi Kelapa Sawit dan Hubungannya dengan Anomali Iklim. https:// agroklimatologippks. files.wordpress.com /2016/07 /ppks.pdf.

Taillez, B.J. 1973. Perhitungan Defisit Air", Bulletin BPPM 4(4): 145-148. 